\title{
Health and Social Outcomes of Moving to a Continuing Care Retirement Community
}

\author{
Elayne Heisler \\ Gary W. Evans \\ Phyllis Moen
}

\begin{abstract}
This study investigates the experience of moving into a continuing care retirement community (CCRC) for those moving locally (intra-county) and from more of a distance (outside the county). Specifically, we compare the social contacts and health of long distance and local movers before and after their moves. A sample of older adults were interviewed a few months before they moved into a Northeast, United States CCRC and a year and a half after they had moved. As predicted, long distance movers were more apt to experience physical health declines in terms of percentage of health conditions experienced, as well as perceived health status. No such health declines were found for local
\end{abstract}

Elayne Heisler, MA, is affiliated with the Department of Sociology, Duke University. Gary W. Evans, PhD is affiliated with the Departments of Design Environmental Analysis and Human Development, Cornell University. Phyllis Moen, PhD, is Ferris Family Professor of Life Course Studies, Departments of Human Development and Sociology, Cornell University.

Address correspondence to: Elayne Heisler, Department of Sociology, Duke University, Box 90088, Duke University, Durham, NC 27708-0088.

This paper is part of the Pathways to Life Quality Study, a collaborative research project conducted by the Gerontology Institute at Ithaca College and the Bronfenbrenner Life Course Center at Cornell University, John A. Krout and Phyllis Moen, Co-Principal Investigators.

Journal of Housing for the Elderly, Vol. 18(1) 2004

http://www.haworthpress.com/store/product.asp?sku=J081

(c) 2004 by The Haworth Press, Inc. All rights reserved. 
movers. Contrary to expectations, the greater health declines of long distance movers were independent of their social network contacts, regardless of whether these relationships were with family or friends. Moreover, our evidence suggests that moving to a CCRC does not affect social integration or perceived social support with distance movers actually more likely than local movers to make new friends within the CCRC. [Article copies available for a fee from The Haworth Document Delivery Service: 1-800-HAWORTH. E-mail address: <docdelivery@haworthpress.com> Website: $<$ http://www.HaworthPress.com> ( 2004 by The Haworth Press, Inc. All rights reserved.]

KEYWORDS. Housing for the aged, continuing care retirement communities, social support, later life moving

More older Americans are relocating than ever before (Longino, 1997). Moreover, we are witnessing a remarkable expansion in senior living arrangements, both in terms of the range of possibilities available and in the construction of new housing facilities. These transformations in housing options point to the need to investigate the health impacts for various sub groups of older adults as they make the transition from independent living in their own homes to adult living in various forms of congregate housing. In this paper, we drew on panel data charting social contacts and health of 92 respondents both before and after they made the residential transition to a Continuing Care Retirement Community (CCRC) in the Northeast United States.

Analyses of demographic patterns of migration over the past few decades have documented three distinct moving patterns and functions in later adulthood. An important stream of research on the geographic mobility of older adults has revealed that it occurs in three distinct phases. The first move occurs at retirement; the second occurs when minor disabilities arise; and the third move follows the onset of major disabilities (Litwak \& Longino, 1990). The first move around the retirement transition is made by individuals between the ages of 60 and 70 seeking lifestyle amenities, such as nice weather and opportunities to pursue hobbies such as boating and golfing. The second move is usually precipitated by health events, most commonly occurring when disabilities make living in one's current residence difficult. Often retirees who moved further from children in their "amenity" move will return to live closer to their adult children as they begin to experience serious health 
problems. The third move is typically made at the end of life and is more common amongst those with intensive illnesses or those who do not have an available caregiver. The frequency of this third move is statistically underrepresented because they are commonly local and hence are not included in migration rates as migration rates do not reflect local mobility (Longino, 1990).

Research on the health outcomes of these various residential transitions of older adults has had to grapple with its complexity. Not only does relocation occur in various phases, moving is also a multistage event, from the triggering events precipitating a move to its impacts on the well-being of both the movers and those left behind (Litwak \& Longino, 1990). There are, to date, inconclusive findings regarding whether and when various moving situations have positive or negative health outcomes. For example, Danermark and Ekstrom (1990) conducted a review of the literature on moving and health effects in older adults. They reviewed more than fifty studies beginning in 1945. Their outcome variable was increases in mortality following location. They found that previous studies have uncovered either increased mortality following relocation or no effects. The magnitude and direction of effects found has varied by the methodology employed. They divide the types of studies into two broad categories: Baseline and experimental. Baseline studies follow a group of movers over time whereas experimental studies compare movers to a control group of non-movers. The studies were also subdivided into comparisons between studies of older adults moving into institutions and those transferring between institutions. Given the disparities in design of the studies they reviewed regarding increased mortality it is not surprising that no conclusive results were found. However, mortality is a catastrophic health outcome and it is important to investigate less extreme consequences. For example, Lawton and colleagues (1970) in a study of older movers found that moving did have profound consequences for health when compared to non-movers matched on social and demographic variables. Specifically, the relocated group had greater declines in functional health.

While moving is a potentially stressful event for people of all ages, older adults may be especially vulnerable given that they have often lived in their former residences for decades and are correspondingly more likely to be socially integrated in the communities in which they live. Such loss of social integration should only occur for those who move long distances but not for those who relocate locally. Moreover, research has shown that social integration predicts psychological health, self-esteem, and life satisfaction in older adults, as well as physi- 
cal health and even longevity (Moen, Dempster-McClain \& Williams 1989, 1992; Moen, Quick, Fields \& Hofmeister, 1999). Older adults who have lived in their homes for many years are less likely to consider relocating either locally or long distance (Robison \& Moen, 1999). Whether or not the outcomes of distance moving differ from those of local moving is an empirical question seldom investigated. There have, however, been studies of how distance determines the site of relocation (Lee, 1991) or how distance affects the relationships between older adults and their children (Dewit, Wister, \& Burch, 1988; Frankel \& Dewit, 1989; Lin \& Rogerson, 1995).

Additional problems exist because research on moving is either prospective, where would-be movers are asked about their expectations of the imminent or potential move, or retrospective, where moving is investigated after the fact. Though moving has been investigated through longitudinal studies, this design is rare. Inconsistencies regarding moving research may also occur because the degree to which the move is voluntary has not been examined systematically (Ferraro, 1982).

Research on moving has commonly been retrospective, asking movers about their moves after they have occurred, or identifying probability of a move. Differences in findings on what occurs may reflect the population studied, such as comparisons across moving from homes to institutions and from one institutional arrangement to another. Furthermore, "institution" has included all types of planned housing for seniors, often failing to differentiate between a full-care nursing home and a planned retirement community. Studies of the health impacts of institutional moves are even more complicated given the growth of housing options for older adults that are neither nursing homes nor conventional retirement communities. They provide a continuum of care, combining independent and assisted living with skilled nursing care. These new housing developments have been termed life care communities or continuing care retirement communities (CCRC). While continuing care facilities were previously limited to a financially advantaged subset of the older population, there is continued growth in the field and expansion in the consumer market, which they serve (Sherwood, Ruchlin, Sherwood, \& Morris, 1997).

Research on moving has tended to miss this more advantaged part of the older population as moving research has focused on institutional transfers, subsidized housing, and the young-old moving to sun-belt areas. Given both the recent development of the CCRC field and their limited population, there has been to date little research investigating the health impacts of moving to continuing care communities. Those 
few scholars who have studied CCRCs tend to focus on financial concerns, in terms of the incidences of use of health care services (Parr, Green, \& Behncke, 1989) and the financial solvency of CCRCs (Somers, 1993). A review of previous research on CCRCs reveals that previous research tends to miss the subjective life quality aspects of living in a CCRC, the present research focuses on this aspect of the CCRC experience.

The general question this research investigated was that of readjusting to a move while losing part or all of one's social network. A social network, defined as "the number and types of ties a person maintains with individuals and groups" (Gottlieb \& Green, 1984, 92), should help to buffer the negative effects of a stressful event. Social networks are also important as they serve as an instrumental linkage to other areas of society. People generally count on their proximate network members to involve them in organizations and activities (Peters et al., 1987). Involvement in organizations and activities, in turn, has positive outcomes for older adults. For retirees, the presence of both activities and community participation are associated with greater quality of life and a more positive well-being. Moen and Fields (1998) found that elderly who volunteer or participate in other organizations have higher self-esteem, greater general life satisfaction, and higher energy levels than non-participants. Volunteering and other forms of social participation were also related to better psychological health. Specifically, retired men and women who felt lonely or who had a sense of boredom had an associated lower sense of mastery, lower self-esteem, and less energy overall. The converse is also true, as very busy retirees felt they had more energy and higher self-esteem on average (Moen et al., 1998). Organization and volunteer activities should increase social interactions and are conducive to friendship formation. Hence, it is likely that involvements and interaction with friends are related, and that changes in both areas may occur simultaneously.

These non-local movers were examined as a population adjusting to a stressful event, while experiencing a simultaneous loss in their social network. Social networks and the social support they provide were examined as a coping resource that one may need to utilize when adjusting to the stressful event of the move. However, the distance one moves may create significant barriers to these resources, as proximity to one's friends and relatives is relevant to the type and frequency of support provided. The combined loss of contact and the loss of actual and instrumental support provided can make a stressful event even more difficult.

The examples of connections between social network and health are extensive. Many variables and measures have been examined in the re- 
lationship of social networks to health with different levels of significance and variations in outcomes observed. As a whole, there appears to be a relationship between the quality and quantity (both actual and perceived) of one's social networks and physical and mental health. Given the importance of a social support network when adjusting to stressful life events and their connection to health, the loss of one's social network were thought to make the non-local adjustment to the continuing care retirement community more difficult than the readjustment of the local movers. Distance movers experience both relocation and a potential decline in social network interaction leaving them doubly at risk for negative health effects. Moving disrupts social bonds; as such it may alter an individual's social networks. Distance from one's former networks may cause the individual to question the availability of those networks in a crisis situation. Though the networks may remain intact, with only the individual moving away, there may be a perception of changes, stress associated with the old networks and fear about their availability. Social networks may also mediate the effects of the move as they may alter the transition to the continuing care retirement community and may promote or inhibit integration into the community. Social support is important in coping with a life change event; it is likely that movers experiencing the same life change but with different amounts of social support will fare differently. Movers here exemplify this: All are moving, but local movers are likely more supported, and thus will fare better.

The hypothesis investigated can be summarized as followed:

1. Distance moved is correlated with negative health outcomes.

2. Social network of distance movers will be more affected by the move. Specifically, number of close friendships of distance movers will be smaller after the move to the CCRC while network size of local movers should be relatively unchanged.

3. The negative correlations between distance of moving $\left(\mathrm{H}_{1}\right)$ will be related to friendships and/or social support.

The nature of the data allowed us to compare physical health changes in long distance and local movers. Negative outcomes in physical health were examined to determine if there were relationships between network changes and negative health outcomes. This study investigated longitudinally the effects that distance has on the presence and intensity of changes in social support networks and health, using distance as an independent variable. 


\section{METHOD}

\section{Sample}

The research reported here draws on panel data to investigate continuity and change in both contacts and health following a move to a continuing care retirement community. We address whether these processes are different for long distance as opposed to local moves. We draw on data collected as part of the Pathways to Life Quality Study (Krout \& Moen, 1996) both before and after the transition to a continuing care retirement community in the Northern United States. One hundred and two people were interviewed in the fall of 1995, several months before they moved into a CCRC. Approximately $73 \%$ of this group were from the surrounding community, while the remainder (27\%) moved from outside of the immediate area (that is, outside the county). We interviewed respondents regarding their housing choices, life history, health and social relationships. A year and half after the move, we undertook follow-up interviews with all our respondents who had moved into the CCRC. Four respondents did not move into the community after all and five had died in the interim. At this point, there were 66 "local" movers and 26 "distance" movers. Although 92 people were interviewed, we had complete information on only 88 respondents. The other four had incomplete information, either because they terminated the interview or did not fill out the self-report booklet. There were no refusals at the time the second interviews were conducted.

Demographic research typically differentiates between movers and migrants. Movers are those who change residences without changing communities (i.e., move locally) while migrants move out of county or further. This classification has been shown to be valid when examining moving in older adults (Biggar, 1980) and is used here to separate the sample into two groups: Those who moved intra-county and those who moved into the county. Distance of move was classified based on respondents' primary residence and not according to any type of temporary housing they may have occupied prior to their move. Due to small sample size it is not possible to further categorize the distance movers by distance from previous residence. In 1995, there were 75 local movers $(73 \%)$ and 28 distance movers $(27 \%)$. There were no significant differences between age, income and educational status in the two groups, both prior to the move and following it.

The average age of the sample is 77, about two-thirds are married, and about $85 \%$ of the respondents have children. Respondents are all in 
relatively good health, all live independently, and few have experienced any declines in their abilities to perform either activities of daily living or instrumental activities of daily living. It must be noted that CCRC residents are not representative of the older population. Generally, CCRC residents are better educated, more financially secure, more likely to be female, and less likely to have a local child than the older population as a whole (Sherwood et al., 1997). The demographic make-up of this sample reflects this (see Table 1). Respondents here are highly educated, with more than half of both groups of movers having a graduate or professional degree. They are also financially advantaged, with an average income between $\$ 75,000$ and $\$ 100,000$, as the screening process to enter the CCRC would assure. Additionally, the sample is nearly two-thirds female, as is typical of retirement community populations.

TABLE 1. Demographic Characteristics by Local/Distance Moving Status

\begin{tabular}{lcc} 
Characteristic & Local Movers & Distance Movers \\
\hline \multicolumn{1}{c}{ Percent (Number) } & Percent (Number) \\
\hline Male & $35.1 \%(27)$ & $28.6 \%(8)$ \\
$\quad$ Female & $62.3 \%(48)$ & $67.9 \%(19)$ \\
Marital Status & & \\
$\quad$ Not Married & $36.4 \%(28)$ & $35.7 \%(10)$ \\
Married & $61 \%(47)$ & $60.7 \%(17)$ \\
Age & & $7.1 \%(2)$ \\
Earliest X- 70 & $10.4 \%(8)$ & $72.0 \%(20)$ \\
$70-79$ & $62.4 \%(48)$ & $18 \%(5)$ \\
$80-84$ & $16.9 \%(13)$ & $0(0)$ \\
$85+$ & $6.9 \%(6)$ & \\
Children & & $7.1 \%(2)$ \\
No Children & $14.3 \%(11)$ & $89.3 \%(25)$ \\
Adult Children & $83.1 \%(64)$ & $2 \%(2)$ \\
Education & & $7.1 \%(2)$ \\
High School/GED/Business/ & $1.3 \%(1)$ & $39.3 \%(11)$ \\
Vocational & & $50 \%(14)$ \\
Some College & $2.6 \%(2)$ & \\
College Degree & $23.4 \%(18)$ & \\
Graduate/Professional & $61 \%(47)$ &
\end{tabular}


Two measures were used to examine health status, since these measures indicate different aspects of health (i.e., difference in severity of conditions, perceived health versus health conditions). Health status was compared between the two groups and initial health (1995) was controlled for in order to determine changes after the move. Health Rating: Health was measured by the respondent's rating of their health on a scale of 0 to 10 . Zero (' 0 ') indicates having "very serious health problems" and '10' indicates being in the "very best of health." Health Conditions: In 1995 there were 24 specific health conditions asked with severity ranging from cancer to allergies. In 1997, the same 24 conditions were asked with two additional conditions. However, for comparability these additional two conditions were excluded. Consequently, the percentage of health conditions present at both Wave I and Wave II were compared based on the initial 24 health conditions.

Networks in this analysis focused on friendships, particularly contact with and support from friends and kinship connections. The number of friends, their location, and contact type and frequency were compared between Waves I and II. New friendships were also examined to determine if distance moved affected the likelihood of making new friends and if this related to health outcomes. Satisfaction with social relationships within the retirement community was examined, using a scale from 0 to 100 rating difficulty of making friendships in the CCRC from 0 'least difficult' to 100 'most difficult'.

Familial networks were measured through frequency and type of contact with network members. The type (face-to-face or by phone) and frequency of contact with children, grandchildren and other relatives was examined in 1995 and changes were then recorded in 1997.

Respondents were asked at both times if they had any local relatives including children that they could count on for help. Presence and absence of local support were measured for each group and changes were noted. Local support should be a measure of availability of the familial social support network and may explain perception of social support at different times.

A measure of perceived social support was obtained using the Social Provisions Scale (Cutrona, Russell, \& Rose, 1986). This scale was included in the self-report booklet, and it identifies how adequately supported individuals feel. It asks the respondents to rate their social relationships and the support received from them on a four point scale. The scale has been shown to have high construct validity, and has negative correlations with depression and positive correlations with life satisfaction. Two sub-scales were used here, social integration and reliable 
alliance. Social integration means " ... a sense of belonging to a group of people who share common interests and recreational activities, usually obtained from friends" (Cutrona, Russell \& Rose, 1986) (sample alpha in $1997=.80)$. Sample items include: "There are people who enjoy the same social activities I do"; "I feel part of a group of people who share my attitudes and beliefs"; "There is no one who shares my interests and concerns"; "There is no one who likes to do the things I do " (Cutrona, Russell \& Rose, 1986). Reliable alliance scores reflect ". . . the assurance that one can count on others for assistance under any circumstances, usually obtained from family members" (Cutrona, Russell \& Rose, 1986, 48) (sample alpha in $1997=.87)$. Sample items include: "There are people I can depend on to help if I really need it."; "If something went wrong, no one would come to my assistance"; "There is no one who shares my interests and concerns"; "There is no one I can depend on for aid if I really need it"; "There are people I can count on in an emergency" (Cutrona, Russell \& Rose, 1986). Both subscales use a four point index where 1 is "strongly disagree," 2 is "disagree," 3 is "agree," and 4 is "strongly agree."

\section{RESULTS}

We first analyzed the links between being a distant or local mover and health. In assessing baseline health (see Table 2) we found that, prior to the move, the distant and local sub samples were in comparable health. However, almost two years following the move to a CCRC the local movers maintained or improved their physical health while the distance movers experienced small declines. Declines were in both objective measures of physical health (such as number of illnesses) and in subjective health measures (such as perceptions of one's physical health). Table 3 confirms that, controlling for 1995 health, we found significant changes in the percentage of illnesses and the health ladder scores among distance movers.

Second, we investigated the mediating role of social integration in accounting for the health declines of distance movers. To do so, we first assessed the impacts of distance status on social connectedness. We found that distance movers experienced more changes in their social network after moving in comparison to local movers. Perceptions of contact, rather than frequency of contact, appear to have been altered by the move. First, following their move to the CCRC, the distance group was less likely to agree that they had as much contact with their family (mean 
TABLE 2. Health Status by Mover Group Before and After Move to a CCRC

\begin{tabular}{|l|c|c|c|c|c|c|}
\multicolumn{4}{c}{ Prior to Move } & \multicolumn{2}{c}{ After Move Change } \\
\hline & Local & Distant & Local & Distant & Local & Distant \\
\hline $\begin{array}{l}\text { \% of } \\
\text { Health } \\
\text { Conditions }\end{array}$ & .121 & .0923 & .1103 & .1491 & -.011 & .057 \\
\hline $\begin{array}{l}\text { Standard } \\
\text { Deviation }\end{array}$ & .0897 & .0708 & .0883 & .1133 & & \\
\hline & & & & & & \\
\hline $\begin{array}{l}\text { Health } \\
\text { Ladder }\end{array}$ & 6.96 & 7.26 & 7.06 & 6.85 & .10 & -.41 \\
\hline Range & $2-10$ & $2-10$ & $2-10$ & $2-10$ & & \\
\hline $\begin{array}{l}\text { Standard } \\
\text { Deviation }\end{array}$ & 2.05 & 2.18 & 2.01 & 1.98 & & \\
\hline
\end{tabular}

TABLE 3. Regression Analysis of Health Variables

\begin{tabular}{|c|c|c|c|}
\hline Variable & $\Delta \mathrm{R}^{2}$ & $\mathrm{~b}$ & $\mathrm{~b}(\mathrm{SE})$ \\
\hline \multicolumn{4}{|l|}{ Equation $1^{\mathrm{a}}$ : } \\
\hline Percent Health Conditions 1995 & $.208^{\star \star \star}$ & .499 & $.587(.110)$ \\
\hline Distant & $.089^{\star *}$ & .302 & $.03327(.010)$ \\
\hline \multicolumn{4}{|l|}{ Equation $2^{\mathrm{b}}$ : } \\
\hline Health Ladder 1995 & $.450^{\star * *}$ & .696 & $.726(.086)$ \\
\hline Distant & $.021^{*}$ & -.148 & $-.360(.200)$ \\
\hline
\end{tabular}

local movers: $3.45(\mathrm{SD}=.65)$; mean distance movers $3.13(\mathrm{SD}=.87)$, $\mathrm{t}(91)=1.62 ; \mathrm{p}<.03$ one-tailed; where 3 = agree $)$. However, measures of frequency of contact did not support this assertion by the distance movers. Distance movers also had less frequent contact with relatives, following their taking up residences in the CCRC, both when compared to before they moved and when compared to local movers after the move. 
Overall, it appears that distance movers contacts with non-relatives, specifically friends, acquaintances, and co-workers were most affected by the move. Distance movers were also dissatisfied with the amount of contact they had with these groups following the move. Distance movers were more likely to disagree that they had as much contact with non-CCRC friends and acquaintances, after moving to the CCRC, whereas local movers were more likely to agree with that statement (mean local movers $=3.01, \mathrm{SD}=.71)$; mean distance movers $=2.17$, $(\mathrm{SD}=.72) \mathrm{t}(91)=4.94, \mathrm{SD}=.60), \mathrm{p}<.000)$. Similarly, local movers agreed that they had as much contact with acquaintances $($ mean $=3.01)$ whereas distance movers disagreed with the same statement (mean $=2.3$, $\mathrm{SD}=.23), \mathrm{t}(91)=4.71, \mathrm{p}<.0002)$. Distance movers also reported that they had seen their friends less often since the move while local movers were more likely to report that their frequency of contact had not changed (mean local movers $=1.83, \mathrm{SD}=.54$; mean distance movers $=1.17, \mathrm{SD}=.39$, $\mathrm{t}(91)=6.34, \mathrm{p}<.000)$.

While we find the predicted changes in objective social network for distance in contrast to local movers, these objective changes failed to mediate the differences in health declines between the two groups. Given this, we also examined perceptions of social support, to investigate both if the objective network changes related to subjective feelings of support, and if this mediated differences in the health declines found between the two groups.

Perceptions of social support remained high and stable following entry into the CCRC, regardless of whether it was a local or distant mover, even with the declines in their objective network. Using measures of perceived support, specifically the Cutrona Social Integration and Reliable Alliance sub-scales, we found perceptions of social support of the two groups appeared to be similar both before and after the move. Both groups prior to the move felt well-supported by their networks (see Table 4). On the Cutrona Reliable Alliance subscale before the move the average score for local movers was $14.00(\mathrm{SD}=2.21)$ and the average score for distance movers was $14.56(\mathrm{SD}=1.53)$ (where 16 indicates the highest levels of support). The score on the Social Integration scales prior to the move to the CCRC were also comparable (local: $13.28(\mathrm{SD}=2.28)$ and distant: 14.13 (SD = 1.52). Perceptions of support remained high and there was little change in the scores of either mover group around the transition to a continuing care retirement community. Post re-location reliable alliance means and standard deviations were 13.92 (1.92) and 
TABLE 4. Cutrona Social Integration and Reliable Alliance Sub-scale Scores

\begin{tabular}{|l|l|l|l|l|}
\hline Variables & $\begin{array}{l}\text { Mean Local } \\
\text { Movers }\end{array}$ & $\begin{array}{l}\text { Standard } \\
\text { Deviation }\end{array}$ & $\begin{array}{l}\text { Mean Distance } \\
\text { Movers }\end{array}$ & $\begin{array}{l}\text { Standard } \\
\text { Deviation }\end{array}$ \\
\hline & & & & \\
\hline Reliable Alliance Wave I & 14.0 & 2.2 & 14.6 & 1.5 \\
\hline Reliable Alliance Wave II & 13.9 & 1.9 & 14.2 & 1.6 \\
\hline & & & & \\
\hline Social Integration Wave I & 13.3 & 2.3 & 14.1 & 1.5 \\
\hline Social Integration Wave II & 13.3 & 2.0 & 13.2 & 1.5 \\
\hline
\end{tabular}

14.24 (1.64) for local and distant movers, respectively with similar, non-significant changes in perceived social integration (13.30[2.00]; 13.20[1.50]). This suggests that, in order to compensate for the reduction in their social network, distance movers actively sought out new sources of support in their new residential environment.

Distant movers do in fact report becoming more involved and having more close friends within their new community. Distant movers were both more likely to report having made new friends in the CCRC and on average had made a higher number of new friends. Both distant movers and local movers agree, that they have made new friends since the move, but distant movers agree with this statement more strongly (mean local movers $=3.41, \mathrm{SD}=.55)$; mean distant movers $3.74(\mathrm{SD}=45$, $\mathrm{t}(91)=12.61, \mathrm{p}<.000)$.

But note that meeting and making friends appears to be relatively easy for all movers to a CCRC. Neither local nor distant movers report that it has been difficult to make friends within the continuing care retirement community, and both groups indicated on a 100 point scale that it had not been difficult to make friends (less than 20). Additionally, both groups rated themselves as 80 or above on a 100 point scale of satisfaction with their friendships. However, distant movers were more likely to name others in the CCRC as close friends than were their local counterparts who continued to have friends in the local community.

While we see both similarities and differences in perceptions of social support and friendships, these factors do not appear to function as a mediator between distance moving and health. Change in health status was unrelated to the development of new social contacts following the move to the CCRC. 


\section{DISCUSSION}

In this study we have attempted to shed light on ambiguity regarding the relation between geographical moves of older adults and health. To do so we: (1) focused on a particular type of move, that of a continuing care community (2) used panel data with information both before and after the move, and (3) located movers in context, by differentiating local from long distance movers. Our findings support the body of research (Lawton, 1975) that suggests that overall voluntary moving is not correlated with negative health outcomes. Lawton and colleagues (1975) observed that the voluntary nature of a move may moderate the negative health consequences experienced. However, the evidence here suggests that moving to a CCRC from a distance may be an unidentified risk factor for adverse health consequences.

Given the fact that we had panel data, we were able to document that there were no significant differences found on any of the health measures prior to the move in 1995. In 1995, this sample was relatively healthy, with over four in five indicating that their self-assessed health (or perceived health) was 'good' or 'excellent'.

However, we observed changes in health status, both in change scores of health measures and in regressions that controlled for initial health status. Both objective health measures (such as percentage of health conditions) and subjective health measures (such as the health ladder and perceive health rating) declined but only for distance movers. Prior to the move, few had experienced (self reported) declines in health activities of daily living. The move to the CCRC was largely proactive, made before any health declines, in part because CCRC's do not enroll applicants with serious health problems.

Because we controlled for pre-relocation health, failing health of the distance group did not motivate their decisions to move to a CCRC and therefore does not account for the subsequent declines in health found among this group. Given the continuum of care present at the CCRC, had severe declines in activities of daily living occurred residents would have moved out of their independent dwellings into the assisted living or nursing facilities. However, all respondents remained in independent dwellings in the CCRC at the time of the second interview, a year and a half post-relocation.

We had hypothesized that objective social integration, in the form of contacts with family and friends, would serve as a mediator between local versus distant moving and health. Thus, we reasoned that distance movers would have fewer such contacts following the move to a CCRC. 
However, this does not appear to explain their declines in health. Moreover, even though objective measures of social integration did change, subjective measures remained unaltered by the move. The changes that did occur in respondents' social network were in their contacts with friends, but not with family. These findings indicate that family ties exist largely independent of geographic location. By contrast, friendships appear to be more dependent on location. These findings support the notion of the 'modified extended family' where kinship bonds adapt to considerable distances between parents and children, given modern communication technology (Litwak 1965, 1985). The contact findings in this sample seem to support this model. Note that few of the respondents had lived near their relatives even prior to the move. Additionally, selection factors may account for this finding, those who move to retirement communities are more likely to be childless. Moreover, those with children who do migrate to retirement communities tend to place less importance on proximity with their children, relatives, and old friends (Sullivan, 1986). Hence selection factors may make distance movers more resilient to network changes. While most of this sample did have children, a larger percentage of local movers (14.3\%) than distance movers $(7.1 \%)$ were childless; it is possible that those who chose to embark on a distance move at late retirement share these attitudes about familial responsibility and proximity. And, as other studies of CCRC have shown (Sherwood et al., 1997), over two out of five (43.6\%) of our respondents indicated that one of their major reasons for moving is that they did not want to be a burden on their family.

Moving did precipitate changes in contact with friends; distance movers were less likely to have local friends even prior to the move, suggesting that they had few proximate contacts to lose, which may have precipitated their decision to move to a CCRC. Following the move, distance movers made more new friends and were more likely to name new friends amongst their closest friends.

Our findings suggest that distance movers become as involved in the CCRC, as were their local counterparts, and actually made more friends in the CCRC. As further evidence of continued integration, perceptions of social support (Cutrona scales) remained high both before and after the move for both mover groups. Distance movers may well experience the loss of social contacts but this is offset by the social connections they find within the CCRC (Lepore, 1992).

We hypothesized that long distance movers would suffer greater ill health than elderly moving locally. This was confirmed by several standardized indices of health. We also predicted that these differences 
would be mediated by the strength of social supportive relationships given that long distance movers would be more likely to experience the disruption of social networks than local movers. This second hypothesis was not supported. This set of findings thus leaves open the interesting and important question-why do more distant movers experience greater ill effects from moving than their locally transplanted counterparts? As indicated there is no evidence that these groups differed beforehand in background variables or in physical health.

We can offer some brief conjectures about why these two groups of migrants may have experienced the move in different ways that could result in differential health effects. One possible reason might relate to the independent and advantaged population that CCRCs particularly, and retirement communities as a whole, tend to attract. Those who make the decision in late adulthood to be self-reliant are likely more independent, and therefore social relationships may matter less to their well-being than to other populations. Another possibility that might explain why the long distance movers may have experienced more severe health consequences is because they experienced a greater degree of disruption in place attachment. Several studies have shown that the sense of familiarity and continuity with geographic location are important to the elderly (Rowles, 1978, Rubinstein \& Parmelee, 1992). Changes in residence, even when voluntary and desirable, disrupt place attachment and produce stress among young adults and youth (Brown \& Perkins, 1992; Michelson, 1970) as well as the elderly (Brown \& Perkins, 1992; Lawton, 1980). Local movers, although changing residence, did not relocate to a new community. The degree of disruption in place attachment may have differed between the two groups. Additionally, Rowles (1978) found in his study that through common involvements, shared values and high levels of interaction individuals come to have similar feelings about places. These feelings become increasingly important to older adults as they withdraw from their actual environment. Given the differences between distance and local movers their feeling about the place may differ.

A third possible reason for the more difficult moving experience of distant migrants might be related to the degree of required changes in life style. The CCRC we studied is located in a small college town with a unique array of cultural and educational activities. It is quite likely that the changes in lifestyle accompanying the move of those from further away were much greater than for those elderly already living locally. All of the local movers resided in or nearby this college town; whereas most of the long distance movers resided previously in metro- 
politan areas or in a few cases, rural areas. Relocations that entail larger changes in lifestyle may be more stressful (Michelson, 1970; Stokols \& Shumaker, 1982). Pre-move intervention programs with senior citizens that enhance the predictability and accuracy of expectations about impending relocation lead to more successful transitions and reduce adverse outcomes including residential satisfaction, physical health, and psychological well being (Pastalan, 1980; Schultz \& Hanusa, 1977). Thus the likely greater degree of life style change experienced by distant vis a vis local movers might also help account for some of apparent ill effects of relocation on the long distance movers.

These speculatations attempt to shed some light on our unexpected findings, while unlikely one cannot limit the possibility that CCRC populations differ significantly from the general population. Continuing care retirement communities attract a unique population, which differs in educational status, income, and racial makeup from the general older population. CCRC residents are also older, have few children (both local and overall), and are more likely to have never married than members of their cohort more generally (Sherwood et al., 1997). CCRC residents and retirement community residents as a whole are more independent than are those in the general older population.

While each CCRC is unique, the community examined here is similar to other continuing care retirement communities. Specifically, Sherwood and colleagues (1997) examined 9 all inclusive CCRCs and the demographic make-up of the communities were not different from the CCRC studied here. Consequently, the findings here may be applicable to other CCRCs. However, there may be differences between already formed communities and incipient communities such as the one examined here, the movers examined in this study were all initial movers to the CCRC. However, studying a newly formed community may be necessary in order to longitudinally examine a large group who move, and this design avoids many of the complications associated with prior cross-sectional studies of movers.

Given trends in longevity and the size of the population that is over 65 along with the increase in housing facilities and options for seniors, including the number of continuing care retirement communities, relocation to such facilities will only increase in the coming years. Our findings point to the importance of considering distance movers as distinct from local movers; though both experience the dislocations associated with moving to congregate housing arrangements in later life, the effects appear to be more profound for distance movers. 


\section{REFERENCES}

Biggar, J.C. (1980). Who moved among the elderly: A comparison of Types of Older Movers. Research on Aging 2 (1), 73-91.

Brown, B.B. \& Perkins, D.D. (1992). Disruptions in Place Attachment. In I. Altman \& S.M. Low (Eds.), Place attachment (pp. 279-304). NY: Plenum.

Cutrona, C., Russell, D., \& Rose, J. (1986). Social Support and Adaptation to Stress by the Elderly. Psychology and Aging 1, 47-54.

Danermark, B. \& Ekstrom, M. (1990). Relocation and Health Effects on the Elderly: A Commented Research Review. Journal of Sociology and Social Welfare, 17, 25-49.

Dewit, D. J., Wister, A.V., \& Burch, T.K. (1988). Physical Distance and Social Contact Between Elders and Their Adult Children. Research on Aging, 10 (1), 56-80.

Ferraro, K. F. (1982). The Health Consequences of Relocation Among the Aged in the Community. Journal of Gerontology, 38 (1), 90-96.

Frankel, B. G. \& DeWit, D.J. (1989). Geographic Distance and Intergenerational Contact: An Empirical Examination of the Relationship. Journal of Aging Studies 3, (2), 139-162.

Gottlieb, N.H., \& Green, L. (1984). Life events, social network, life-style, and health: An analysis of the 1979 National Survey of Personal Health Practices and Consequences. Health Education Quarterly, 11, 91-105.

Kaye, L.W. \& Monk, A. (1991). Social Relations in Enriched Housing for the Aged: A Case Study. Journal of Housing for the Elderly, 9 (1/2), 111-126.

Krout, J. \& Moen, P. (1996). "Pathways to Life Quality Study: Progress Report 1996." Ithaca, New York.

Krout, J.A., Moen, P., Oggins, J., Holmes, H.H., \& Bowen, N. (2000). "Reasons for Relocation to a Continuing Care Retirement Community." Pathways Working Paper \#00-04. Ithaca, NY: Bronfenbrenner Life Course Center.

Lawton, M.P. (1975). Planning and Managing Housing for the Elderly. New York: Wiley.

Lawton, M.P. (1980). Environment and Aging. Monterey, CA: Brooks-Cole.

Lawton, M.P. \& Yaffe, S. (1970). Mortality, Morbidity and Voluntary Change of Residence by Older People. Journal of the American Geriatrics Society, 18 (10), 823-831.

Lee, C. (1991). Models of Migration Decision Making Reexamined: The Destination Search of Older Migrants to Cape Cod. The Gerontologist, 31 (2), 204-209.

Lee, G. R. \& Ishii-Kuntz, M. (1988). Social Interaction, Loneliness, and Emotional Well-Being Among the Elderly. Research on Aging, 9 (4), 459-482.

Lepore, S. J. (1992). Social Conflict, Social Support, and Psychological Distress: Evidence of Cross-Domain Buffering Effects. Journal of Personality and Social Psychology 63 (5), 857-867.

Lin, G. \& Rogerson, P.A. (1995). Elderly Parents and the Geographic Availability of Their Adult Children. Research on Aging. 17 (30), 303-331.

Litwak, E. (1965). Extended Kin Relations in an Industrial Democratic Society. In E. Shanas \& G.F. Streib (Eds.), Social Structures and the Family: Generational Relations (pp. 290-323) Englewood Cliffs, NJ: Prentice Hall. 
Litwak, E. (1985). Helping the Elderly: The Complementary Roles of Informal Networks and Formal Systems. New York: The Guilford Press.

Litwak, E. \& Longino, C. F. (1987.) "Migration Patterns Among the Elderly: A Developmental Perspective." The Gerontologist, 27 (3), 266-272.

Longino, C. F. (1997). On the Move: The New Migration Patterns of Older Americans. Lifestyles of the Aging, 1, (Spring), 23.

Michelson, W. (1970). Man and His Urban Environment. Reading, MA: Addison Wesley.

Moen, P., Fields, V., Quick, H., and Hofmeister, H. (2000). A life course approach to retirement and social integration. pp. 75-107 in K. Pillemer, P. Moen, E. Wethington, and N. Glasgow (Eds.), Social Integration in the Second Half of Life. Baltimore, MD: The Johns Hopkins Press.

Moen, P., Dempster-McClain, D., \& R. Williams, Jr. (1992). "Successful Aging: A Life Course Perspective on Women's Roles and Health.” American Journal of Sociology, 97 (6): 1612-1638.

Moen, P., Dempster-McClain, D., \& R. Williams, Jr. (1989). "Social Integration and Longevity: An Event History Analysis of Women's Roles and Resilience.” American Sociological Review, 54: 635-47.

Pastalan, L.A. (1980). Relocation, mortality, and intervention. Annual Convention of the American Psychological Association. Montreal. September, 1980.

Parr, J., Green, S., \& Behncke, C. (1989). What People Want, Why They Move, and What Happens After They Move: A Summary of Research in Retirement Housing. Journal of Housing for the Elderly, 5, 7-33.

Robison, J. T., \& Moen, P. (2000). Future housing expectations in late midlife: The role of retirement, gender, and social integration. Pp. 158-189 in K. Pillemer, P. Moen, E. Wethington, and N. Glasgow (Eds.), Social Integration in the Second Half of Life. Baltimore, MD: The Johns Hopkins Press.

Rowles, G. D. (1978). Prisoners of Space? Exploring the Geographical Experience of Older People. Boulder: Westview Press.

Rubinstein, R.L. \& Parmelee, P.A. (1992). Attachment to place and the representation of the life course by the elderly. In I. Altman \& S.M. Low (Eds.), Place Attachment (pp. 139-164). NY: Plenum.

Schultz, R. \& Hanusa, B. H. (1977). Facilitating institutional adaptation of the aged. American Gerontological Society. San Fransisco. August.

Sherwood, S., Hirsch S., Ruchlin, C., Sherwood,C. \& Morris, S.A. (1997). Continuing Care Retirement Communities. Baltimore. MD: John Hopkins University Press.

Somers, A. R. (1993). 'Lifecare': A Viable Option for Long-Term Care for the Elderly. Journal of American Geriatrics Society, 41, 188-191.

Stokols, D. \& Shumaker, S.A. (1982). The psychological context of residential mobility and well being. Journal of Social Issues, 38, 149-172.

Sullivan, D. A. (1986). Informal Support Systems in a Planned Retirement Community: Availability, Proximity, and Willingness to Utilize. Research on Aging, 8, (2), 249-267. 